\title{
The front-end of eco-innovation for eco-innovative small and medium sized companies
}

Journal of Engineering and Technology Management, Volume 31, January-March 2014, Pp. 43-57

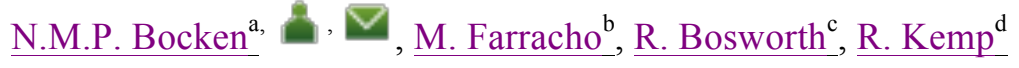

${ }^{a}$ Institute for Manufacturing, Department of Engineering, University of Cambridge, Cambridge

CB3 0FS, United Kingdom

${ }^{\mathrm{b}}$ ICIS, Maastricht University, Maastricht $6200 \mathrm{MD}$, The Netherlands

${ }^{c}$ Department of Management and International Business, University of Auckland Business

School, Auckland, New Zealand

${ }^{\mathrm{d}}$ ICIS and UNU-MERIT, Maastricht University, Maastricht $6200 \mathrm{MD}$, The Netherlands

\begin{abstract}
This paper studies the Front End of Eco-Innovation (FEEI), the initial phase of the ecoinnovation process. Incorporating environmental concerns at the front-end of innovation is important, as product parameters are still flexible. This paper investigates the FEEI for 42 small and medium sized eco-innovators in the Netherlands by using a survey. The results show that SMEs embrace informal, systematic, and open innovation approaches at the FEEI. Teams appear to be multidisciplinary, and creativity and environmental knowledge are essential. Experimentation played a significant role at the FEEI. The paper concludes with recommendations for future research and implications for managers.
\end{abstract}

Key words: fuzzy front-end; eco-innovation; eco-design; new product development; sustainability

\section{Background}

To reduce environmental pressures caused by a growing and developing global population demanding more products, eco-innovations are important: competitively priced products and technologies with better environmental performance than relevant alternatives. Reid and Miedzinski (2008) define eco-innovation as the creation of novel and competitively priced goods, services, systems, processes, and procedures to satisfy human needs and provide a better quality of life for everyone with a life-cycle minimal use of natural resources per unit output, and minimal release of toxic substances.

Eco-innovations may be new to the world or new to the company adopting it (Arundel and Kemp, 2009, Kemp, 2010 and Bocken et al., 2012) and may lead to varied levels of environmental improvement. In this paper, the focus is on new to the world eco-innovations 
created by frontrunner companies: defined here as those companies, which have created ecoinnovations with significant environmental benefits compared to industry incumbents (established firms in an industry).

The front-end process of eco-innovation - defined in this paper as the initial stages of the ecoinnovation process - is considered to be an important stage for the ultimate performance of products; because once product specifications are decided upon, only minor changes concerning the sustainability of the product can be made (Herstatt and Verworn, 2001). Research focused specifically on the front-end stages of innovation has received increasing attention through the past decade, both within academia and among industry practitioners. Example contributions include Kim and Wilemon's (2002) strategies for managing the front-end process, Reid and de Brentani's (2004), initial framework to explain the fuzzy front-end, and de Brentani and Reid (2012) description of the roles of key individuals in the fuzzy front end of innovation. Koen et al. (2002) identified various tools and mechanisms, to be effectively used at the front end of innovation such as technology roadmapping, (competitive, customer and technology) trend analysis and scenario planning. Kurkkio et al. (2011) investigated front-end activities for process innovation.

In contrast, the Front-End of Eco-innovation has received little attention in the literature. The front-end of eco-innovation can be expected to be different from the front-end of normal innovation in the sense that special knowledge and tools are needed for dealing with environmental issues. Motivations of responsibility may also play a bigger role. The need for eco-innovation is increasingly recognised and viewed as becoming even more urgent in a world of a growing population and changing consumption pattern (The Royal Society, 2012). Integrating environmental aspects at an early stage in the design of products has the benefit of minimising environmental impacts right from the start. Once product specifications are being made, only minor changes are usually possible. Hence, the Front End of Eco-Innovation (FEEI) is becoming an increasingly important area of investigation.

Despite the attention given to eco-innovation by business, academia and governments, there is limited understanding of how initial new ideas and concepts develop (e.g., at the shop floor or an organisation's research and development lab), and how these ideas become the basis for product development. Moreover, there is little understanding of organisational mechanisms, tools, activities and techniques employed within innovation projects, which enable environmentalspecific innovation to arise and commercialise in particular in the early stages of the innovation process.

This paper draws on the front-end of innovation literature, but sets out to make an empirical research contribution by considering FEEI activities by small and medium-sized companies (SMEs), as there is little research to date on this topic. The literature on innovation for sustainability largely focuses on large companies (Bos-Brouwers, 2010). This research also seeks to make a contribution to the limited literature on eco-ideation (Nissen, 1995 and Bocken et al., 2011 are two of the few examples) by investigating eco-ideation processes for the research sample. The main research question investigated in this paper is: How do eco-innovators undertake the front-end stage of eco-innovation projects, which lead to advancements towards 
environmental sustainability? As this is a broad question, the following four sub questions are investigated in particular:

1. What are the drivers for eco-innovators?

2. What are the mechanisms and tools used for idea generation?

3. Who is engaged in the FEEI and which skills are required?

4. With which external parties do SMEs interact and how?

\section{The front-end of innovation and eco-design in the literature}

The front-end of innovations and eco-design tools and concepts have independently been discussed extensively in the literature, but the combined area of front-end eco-innovation has received little attention. This section explains the rationale for this research.

\subsection{Why is the FEEI important?}

The Front-End of Innovation (FEI) is the initial phase of the innovation process "where product strategy formulation, opportunity identification, and idea generation take place and decisions about new product development are taken" (Hassi et al., 2009). The FEI is also referred to as the "fuzzy" front-end of innovation (e.g. Koen et al., 2002) or the discovery phase, the initial stage of the product design process, which is followed by initial idea screening ("scoping"), to more detailed screening processes, development, and testing and product launch (Cooper, 2008). According to Brem and Voigt (2009) the FEI encompasses the entire time spent on the idea, from either an internal or an external source, and takes place prior to a first official discussion of the idea. Building on these definitions, the Front-End of Eco-Innovation (FEEI) is defined as the initial phase of the eco-innovation process.

The FEI is viewed as the key contributing factor for product innovation and present it as the phase with greatest opportunity for improving the overall innovation process (Koen et al., 2001). For companies to achieve true sustainability as opposed to a lower level of sustainability, considerations for sustainability have to be incorporated in early stages of the innovation process as argued by Ehrenfeld (2008). Herstatt and Verworn (2001) found that at the beginning of the process, the influence on the outcome is extremely high and it diminishes as the time spent on the innovation process flows. At this stage the cost of changes are lowest in the innovation process. Moreover, Khurana and Rosenthal (1998) argue that the most significant benefits can be achieved through improvements in the performance of the front-end activities. Hence, this stage is critically important for the success of the innovation.

\subsection{The FEEI for SMEs}

SMEs have been under-researched in the area of sustainability (Bos-Brouwers, 2010) but they are of great research interest because they make up a large part of industry activity: $99 \%$ of EU companies are SMEs (EU, 2012), about 50\% of GDP in high-income countries comes from SMEs (Ayyagari et al. 2007), and SMEs are responsible for two-thirds of private sector employment (EU, 2012). The importance of eco-innovation research for SMEs is described by the EU (2012) as following: "First, many SMEs could benefit by introducing eco-innovative 
approaches into their operations. Second, SMEs, and especially start-ups, can be the ideal incubators for eco-innovation, and can bring to market new, less environmentally damaging products, services and processes".

Building on a large literature base, Bos-Brouwers (2010) developed a comparison of advantages and disadvantages of SMEs as opposed to large companies (Table 1). Because of their structure, SMEs may be "better" at being innovative and the FEEI. Chandy and Tellis (2000) suggest that dynamic organisational structures and strong technological capabilities can make large organisations more innovative. This means that large companies, which have separate innovation business units, mimicking small company structures can be innovative, having the small company advantage of agility and a wider resource base. Eco-innovation may also be more suited for start-ups. As Christensen (1997; P. XV) argues: disruptive innovation may initially result in worse product performance, and products generally have new fringe benefits (low cost, convenience, smaller and simpler) compared to the market standard. Hence, they may appeal less to incumbent organisations in an industry, which focus on serving the mass market. This implies that it is important to investigate the FEEI for start-ups and SMEs, who (initially) serve a smaller market.

\begin{tabular}{|c|c|}
\hline SMES & Large companies \\
\hline Advantages & Advantages \\
\hline $\begin{array}{l}\text { Flexibility of organisation- Less bureaucratic, } \\
\text { Responsiveness to changing circumstances, Internal } \\
\text { communications faster and more efficient) }\end{array}$ & $\begin{array}{l}\text { Financial - Less difficulties attracting capital and bank } \\
\text { investments, Innovation risks averted by diversity in } \\
\text { projects }\end{array}$ \\
\hline $\begin{array}{l}\text { Owner/manager - Dynamic, entrepreneurial - Horizontal } \\
\text { leadership style, Direct role in innovation as ideas } \\
\text { generator } \\
\text { Disadvantages }\end{array}$ & $\begin{array}{l}\text { Labour - Less difficulties in attracting skilled labour } \\
\text { Knowledge - Participation in networks and conference } \\
\text { visits to update knowledge, Information management } \\
\text { systems }\end{array}$ \\
\hline $\begin{array}{l}\text { Owner/manager - Poor managerial skills, Dependency } \\
\text { on, Lack of formalised planning } \\
\text { Financial - Difficulties attracting venture capital and } \\
\text { bank investments, Failure of innovation projects may be } \\
\text { financially disastrous, High fixed costs for technological } \\
\text { investments and start-up) } \\
\text { Labour - Difficulties attracting skilled personnel - } \\
\text { Harder to update technological knowledge }\end{array}$ & $\begin{array}{l}\text { Management - Decentralised management style with } \\
\text { decision power on lower levels in the organisation, } \\
\text { Long-term strategic management capabilities } \\
\text { Disadvantages } \\
\text { Management - Top management isolated from } \\
\text { customers and work floor - Emphasis on short-term } \\
\text { cost-cutting instead of long-term infrastructural } \\
\text { enhancements } \\
\text { Labour - No entrepreneurial fanatics tolerated } \\
\text { Flexibility of organisation - Bureaucratic, highly } \\
\text { formalised organisation structure }\end{array}$ \\
\hline
\end{tabular}

Table 1. Comparison of SMEs and large companies. Source: Bos-Brouwers (2010) 


\subsection{Research gap}

The FEEI phase for SMEs appears to have received little attention in the literature. Specific contributions include Buttol et al. (2012) who developed an ICT platform to support ecoinnovation in SMEs, Bos-Brouwer (2010), who investigated innovation for sustainability in SMEs (but not the front-end in particular) and Van Hemel and Cramer (2002) who investigated eco-design for SMEs. This research seeks to contribute to this area by investigating FEEI as undertaken by SMEs.

\section{Development of a survey on FEEI by SMEs}

The development of the survey questions to explore how eco-innovative SMEs companies might undertake the FEEI is discussed in this section.

\subsection{SME motivations for the FEEI}

The rationale for SMEs to engage in eco-innovation may be diverse. Van Hemel and Cramer (2002), based on a research in SMEs, found that the most influential external stimuli for ecodesign included 'governmental legislation', 'customer demands' and 'industrial sector initiatives'. Bos-Brouwers (2010) found that the majority of SMEs have moved beyond compliance as a driver for sustainability activity; many sustainable innovations are directed at the improvement of eco-efficiency (cost-effectiveness), but value creation (business opportunity) is also important.

To identify the main reasons for SMEs to engage in eco-innovation the following question was posed:

- What are the drivers for eco-innovation? What environmental targets are set?

From the literature (e.g. Bos-Brouwers, 2010) it appears that SMEs have moved beyond pursuing eco-innovation to comply by legislation. To investigate whether this is the case, the importance of the government is investigated:

- How important is the role of the government to stimulate eco-innovation?

\subsection{Practices for effective FEEI management by SMEs}

What does effective FEEI management look like? Johansson (2002) identified the following factors that contribute to successful integration of eco-design in product development: management (e.g. clear goals); customer relationships; close supplier relationships; consideration of eco-design at the beginning of product development; competence (e.g. training) and motivation (e.g. assigning an environmental champion). Boks (2006) identified management support, the use of environmental checkpoints and roadmaps, and customised eco-design tools as success factors to early product development success. Similarly, Petala et al. (2010) found that senior management commitment is important for the integration of sustainability in new product development. Moreover, sustainability goals need to be integrated in the project brief; regular training and education may encourage the use of eco-design tools, and cooperation between different functional areas (e.g. design, marketing) are required (Petala et al., 2010). Team 
diversity may contribute to creativity if managed well (Kurtzberg, 2005). However, because of the size of SMEs, their choice of potential team members may be limited.

Research on effective FEEI has mainly focused on how large companies perform this (e.g. Petala et al., 2010). To gain more insights into individual involvement in the FEEI by SMEs, the survey investigates the following for SMEs:

- Which staff members are involved at the FEEI?

- Which skills are required at the FEEI?

Both informal and formal activities may be important for the innovation process (Kurkkio et al., 2011; Khurana and Rosenthal, 1998). Based on in-depth case studies, Khurana and Rosenthal (1998) characterised formal-driven FEI by process orientation, explicitness of product definitions and a broad business perspective while a culture-driven approach is characterised by a strong organisational culture and cross-functional interactions, "subtle control" and deep understanding of new product development by key organisational members. Bertels et al. (2011) describe that there is a lack of "collective tacit knowledge" at the FEI. According to Bertels et al. (2011) tacit knowledge may be transferred from situational learning (learning in context and practice); support of existing communities of practice (e.g. through IT), the freedom to participate in such communities and an open climate contribute positively to FEI. Khurana and Rosenthal (1998) propose product strategy (e.g. product positioning), product definition (e.g. preliminary market assessment), project definition (e.g. resource allocation), and organisational roles (e.g. project team) as crucial front-end success and failure factors, thus formalising many of the processes at the potentially "fuzzy" front-end. A combination of formality and informality may be encouraged or even institutionalised in organisational practices. The following question is posed to investigated the level of formality of the FEEI for SMEs:

- How formal is the FEEI for SMEs?

\subsection{Tools used at the FEEI}

Eco-design is "the integration of environmental considerations in product development" Karlsson and Luttropp (2006, p. 1292). Synonyms for eco-design include green design, design for X (e.g. waste reduction) and dematerialisation (i.e., reducing the amount of waste generated per industrial product, as defined by Herman et al., 1990).

A large number of eco-design tools have been developed as a result of interest in the area. Based on Baumann et al. (2002), Byggeth and Hochschorner (2006) and Bocken et al. (2011) ecodesign tools can be classified as guideline, evaluative, comparative, trade-off and eco-ideation tools. Luttropp and Lagerstedt's (2006) 'Ten golden rules' is an example of a checklist developed based on guidelines from companies (e.g. use resources efficiently) such as Volvo. The eco-design strategy wheel by Van Hemel and Cramer (2002) based on Van Hemel and Brezet (1997) is a comparative tool to compare the environmental performance of multiple products. The Materials Energy \& Toxicity (MET) matrix (Van Berkel et al. 1997) is an example of an evaluative tool based on Life Cycle Assessment (LCA) principles. Trade-off tools include Philips' STRETCH, an acronym for selecting Strategic Environmental Challenges (Cramer and Stevels, 1997), a tool to evaluate environmental impact reduction potential and strategic opportunities of innovations; and BASF's eco-efficiency analysis, which compares environmental impacts against costs (Saling et al., 2002). Eco-ideation tools aim to inspire users 
to generate new product and process ideas, and include the approach by Nissen (1997) and Bocken et al. (2011).

Some eco-design approaches are largely conceptual (e.g. bio-mimicry, industrial ecology and cradle-to-cradle) and depend on the creativity of an individual or facilitation by those familiar with the method. Biomimicry "studies nature's models and then imitates or takes inspiration from these designs and processes to solve human problems" (Benyus, 1997). Products developed using cradle-to-cradle principles (McDonough and Braungart, 2002) involve closed-loop systems in which every output can either biodegrade naturally and restore the soil (the biological cycle) or can be fully recycled into high quality materials for subsequent product generation (the technical cycle).

Other frameworks are intended for a detailed expert analysis of a product based on which improvement targets may be set, such as Life cycle analysis (LCA). LCA addresses the environmental aspects and potential environmental impact throughout a product's life cycle from raw material acquisition through production, use, end-of-life treatment, and disposal as described in the International Standard for Environmental management, Life cycle assessment, principles and framework (ISO 14040, 2006).

From the above, it appears that many eco-design tools are evaluative and suited for later stages of the product innovation process, rather than idea-generative and suited for the FEEI (Bocken et al., 2011). Moreover, many eco-design tools are conceptual and require specific personal skills or expert facilitation or involve detailed analysis of a product and are therefore suited for later stages of the product innovation process (Bocken et al., 2012). Integrating sustainability at early stages of the product innovation process is important, although few tools are available for this. The survey investigates which tools, concepts and mechanisms (resource-limited) SMEs use for their innovation process:

- Which eco-innovation tools and concepts, mechanisms and processes are used by SMEs?

\subsection{Involvement of external parties}

Effective FEI management may lead to a strong competitive advantage (Kim and Wilemon, 2002). The FEI is influenced by the outside world (e.g. economic development), organisational capabilities, competitor and customer influences, and the depth and strength of enabling sciences and technology, as summarised in Koen et al. (2002). FEI success depends on the company's ability to change strategy and plan when the environment changes, a supportive culture, senior involvement, constancy of purpose and aggressive goals (Koen et al., 2002). As an outside perspective appears important at the FEEI, the following survey questions were included:

- Which external parties do SMEs engage with?

- Which external information channels are used?

- What are the mechanisms are used for interaction, and to store and share external trends?

\subsection{The survey}

The survey questions each contained multiple-choice responses based on the literature plus open space to be used by the respondents for their personal answers, which could not be captured by the structured responses. The full list of survey questions and answers is available upon request. 


\section{Sample of eco-innovators selected for survey}

The sample consists of 42 Dutch SMEs who applied for the Dutch Ei van Columbus (Het Ei van Columbus, 2010; Translation: “Columbus' Egg” ) prize for sustainability innovations and agreed to participate in our survey. The Dutch Ei van Columbus is a national prize in the Netherlands, which is awarded to the best sustainable innovation in organisations (profit and notfor-profit) of all sizes. The prize is intended to reward sustainable companies and encourage the further development of sustainable innovation by recognising the efforts of frontrunners. The sample included the companies who applied for this prize (so not only the winners) so it is a sample of self-selected eco-innovation frontrunners.

The survey (available upon request) was executed in English. Although the survey contained no question regarding the position of the respondent, the SMEs were phoned in anticipation of the survey to identify the right person to send the survey too. The authors asked for the contact details of those responsible for the application of the Ei van Columbus prize and those responsible for the innovation process. It should be noted that in SMEs people may have multiple roles (because of the small size of the company) but the survey did not include a question on the specific roles of the person (except for their involvement in the innovation process and Ei van Columbus prize).

Hundred-and-two companies whose innovation appeared to be an eco-innovation were contacted by phone, and 91 agreed to participate. Each of these 91 companies was emailed further information on the research topic and a link to the online survey. Eventually 57 companies answered the survey but only 42 responses were considered usable; 15 responses were excluded because of the following:

- Three companies classify their environmental performance as "below average" or "far below average" and this paper focuses on eco-innovative front-runners.

- Two responses originated from companies with more than 500 employees. These two responses were excluded to focus on SMEs, because SMEs by definition, typically do not have more than 500 employees.

Ten surveys were excluded because of incomplete responses. The SMEs whose answers were used ( $n=42)$ were all manufacturing companies, across a wide range of sectors ( Appendix A); 11 SMEs had fewer than 50 employees, 24 had 50-100 employees, and 7 had 100-250 workers. Twenty-seven companies identified themselves as "best 10\%", 12 as "above average, and 3 as "average". Twenty-one SMEs identified their customers as Business-to-Business (B2B), 3 as Business-to-Customers (B2C) and 18 as both.

To better understand the results, four in-depth semi-structured interviews were conducted. Two interviews were excluded from the analysis because these were from large companies, and there were too few responses (only two) from large companies to make meaningful comparisons against the SME responses. The two remaining companies are: PaperFoam and Haynest. Although in the same sector (packaging), the companies are quite different: PaperFoam is an incumbent and Haynest is a start-up company. 
PaperFoam is a private limited Dutch company, established in 1998 in the Netherlands, and produces environmental friendly packaging, made of starch, cellulose and water. The final product can be recycled as paper or composted to biodegrade (PaperFoam, 2010). PaperFoam aims to reduce greenhouse gas emissions and manufacture products, which use far less nonrenewable energy than competing products. PaperFoam is currently working on the development of a system to allow them to re-use the product, and its waste.

Haynest is a start-up company, which has developed biodegradable, compostable packaging material as an eco-alternative for expanded polystyrene (EPS) and moulded paper packaging. The product is produced according to the cradle-to-cradle principle. "Sustainability, renewability, raw material efficiency and low energy consumption are deeply embedded in the corporate strategy of Haynest" ( Haynest, 2010). According to its founder (Knoors, 2010) the idea for Haynest originated from a company that wanted to pack "naturally" and could not find packaging to satisfy this need. The production process of Haynest is simple: the main input is grass dried by the sun, which is cut in pieces; a bio binder is added and the mass is put in moulds to dry. The company is developing manufacturing equipment and aims to sell its product patents and machinery to allow their innovation to be globally distributed and minimise global transportation of the end product (the natural packaging) because raw materials can be locally sourced.

\section{Results}

This section discusses the main survey results based on the 42 responses of front-runner ecoinnovator SMEs in The Netherlands. Although the survey contained 32 questions around the themes of SME drivers for eco-innovation, mechanisms and tools used, people and skills, and specific practices only the main results are presented in this section. The full survey outcomes are available upon request. Only the main responses per question are included in this results section. ${ }^{1}$ The respondents used the 'other' category for open responses very sparingly. This may have been the case because the survey already included long lists of closed responses. Hence, the top responses generally include the 'closed' ones from the questionnaire.

\subsection{Eco-innovation focus}

About $50 \%$ of the SMEs in the survey had been engaged in eco-innovation for less than three years, nearly $17 \%$ from 3-10 years, and 33\% more than 10 years. Most innovations are product eco-innovations $(33 \%)$, or a combination of product- and process innovation $(62 \%)$ rather than pure process innovations (5\%). Knoors (2010) gives the following reasons to work on product and process innovation: "the production process needs to be "eco" because it lowers costs, which is very important because we cannot sell the product at a higher price than the traditional material. So we put a lot of attention to the energy use, which is the main cost in our production process". Paperfoam focuses on product rather than process innovation, because process change

\footnotetext{
${ }^{1}$ Top scoring responses in this section generally included those responses, which were given the highest or second
} 
is seen as difficult and costly. Geerts (2010): "If you look at our building you notice we are not in a very ecological building so we could use a better building and reduce our own carbon footprint. Our machines are not yet totally optimized (...) but actually we are not changing it because it is too expensive in the short run". The fact that Haynest is a start up, and PaperFoam is nearly 15 years old, could explain differences in their innovation focuses.

\subsection{SME motivation and strategies for FEEI}

\section{What are the drivers for eco-innovation?}

The most important motivation for the eco-innovation projects is potential revenue (Table 2). Two other important drivers are technological advancements and personal reasons - nearly $90 \%$ of respondents found each of these drivers reasonably to critically important. Positive experiences and Image were reasonably important for nearly $80 \%$ of all respondents. Ecocertifications, supplier pressure, consumer and competitive pressure, legislation and export standards are least important (less than $30 \%$ of respondents found these critically important and less than $60 \%$ found these critical).

\begin{tabular}{|l|l|}
\hline Drivers & Number of respondents who found this driver critically important \\
\hline Potential revenues & 28 out of $42(67 \%)(98 \%$ found this reasonably or critically important) \\
Personal reasons & 22 out of $42(52 \%)(88 \%$ found this reasonably or critically important) \\
Positive experiences & 16 out of $42(48 \%)(88 \%$ found this reasonably or critically important) \\
Improved image & 15 out of $42(36 \%)(81 \%$ found this reasonably or critically important) \\
\hline
\end{tabular}

Table 2. Main responses on survey question: "Please select the level of importance the following drivers that primarily prompted your company to become active in eco/sustainability issues" (4-point Likert-scale from "not at all important" to "critically important").

The eco-innovations appear to be opportunity-driven and building on past positive experiences. Although in our sample eco-innovations are mainly revenue-driven, personal motivation is found to be critical. Kurkkio et al. (2011) found that process innovation ideas that originate from top or middle management more easily gain legitimacy than those from development personnel. Not surprisingly, strong personal motivations of the founder or management are important to drive eco-innovations forward.

\section{Which environmental targets are considered when developing eco innovative products?}

The most important environmental targets of companies in the sample are (toxic) waste reduction and emissions reductions (Table 3 ). The attention given to these concepts is in line with ecodesign tools. For instance, the "Ten Golden Rules" (Luttropp and Lagerstedt, 2006) suggest that companies should minimise resource (e.g. energy) and toxic substance use and waste. For over $50 \%$ of the respondents these three aspects are top priority at the FEEI. The reduction of water 
consumption is considered least relevant, which may be a country-specific result as in the Netherlands water scarcity is not a pressing problem.

\begin{tabular}{|l|l|}
\hline $\begin{array}{l}\text { Environmental } \\
\text { innovation targets }\end{array}$ & Number of respondents who found this critically important \\
\hline Waste & 23 out of $42(55 \%)(83 \%$ found this reasonably or critically important) \\
Toxic waste & 23 out of $42(55 \%)(78 \%$ found this reasonably or critically important $)$ \\
Durability & 22 out of $42(52 \%)(86 \%$ found this reasonably or critically important) \\
Renewable resources & 19 out of $42(45 \%)(78 \%$ found this reasonably or critically important) \\
Energy & 17 out of $42(40 \%)(78 \%$ found this reasonably or critically important $)$ \\
\hline
\end{tabular}

Table 3. Main responses on survey question: "Please rank the level of importance that your company confers to the following environmental innovation concepts when developing eco innovative products" (4-point Likert-scale from "not at all important" to "critically important").

Energy, renewable resources, and durability are reasonably to critically important for about $80 \%$ of all respondents when developing eco innovative products. This suggests that environmental concerns are pragmatic and aligned with 'conventional' business concerns such as quality (durability) and cost (energy).

\section{Which environmental factors are in daily operations?}

The resource price is the environmental factor of most concern in daily operations (Table 4), whereas factors such as carbon emissions, climate change, green procurement, pollution levels, and nature conservation are of less concern in day-to-day operations (considered 'all the time' by only less than $25 \%$ of respondents). Again this suggests that day-to-day environmental concerns are aligned with direct business concerns such as the price of resources and consumer demand).

\begin{tabular}{|l|l|}
\hline Environmental factors & Number of respondents who took this into account all the time \\
\hline Resource price & 25 out of $42(60 \%)(91 \%$ took this into account at least some of the time) \\
"Green" consumer demand & 17 out of $42(40 \%)(71 \%$ took this into account at least some of the time) \\
\hline
\end{tabular}

Table 4. Main responses on survey question: "Please select the frequency by which the following environmental factors are taken into account by your company when investigating the development and conceptualisation of environmental related innovations." (4-point Likert-scale from "not at all" to "all the time"). 


\section{How important is the role of the government to stimulate eco-innovation?}

Government influence varied between companies. Nearly $70 \%$ of the respondents received government support. In addition it was found that nearly $30 \%$ of the companies regard legislation as a 'critically important' driver, while $40 \%$ of the respondents do not perceive this to be a very important driver. According to Knoors (2010) government support was a critical factor for the development and testing of new ideas leading to Haynest. Paperfoam produces lighter weight packaging material, which has tax advantages (packaging is taxed based on weight in the Netherlands) and benefits for eco-conscious customers. Government influence thus may be critical to help companies go beyond the idea phase and may encourage initiatives through tax benefits.

\subsection{Practices for FEEI management by SMEs}

\section{Is the FEEI formalised?}

According to the survey, $88 \%$ of eco-innovators have a deliberate strategy to improve or change the environmental aspects of their products, processes or services, and 95\% agree that ecoinnovation plays an important role in their corporate social responsibility or sustainability strategy. However, $60 \%$ of the eco-innovators acknowledged the process of generating ecoinnovative ideas is 'quite informal' and only $12 \%$ of the respondents declared this initial phase is 'always formally driven'.

\section{Which staff members are involved at the FEEI?}

Many functional areas are involved in eco-innovation projects: top management, Research \& Development $(R \& D)$, marketing, sales, engineers, and designers. This is in accordance with Luttropp and Lagerstedt (2006) who argue eco-innovation teams should be multifunctional because of the multifaceted character of eco-innovation, and because sustainability metrics should be balanced against other product characteristics. Top management and R\&D have a slightly higher level of involvement than other company members (for more than $60 \%$ there was 'high involvement', and for over $80 \%$ there was 'medium involvement' from these groups), but overall eco-innovation appears to be a collective endeavour involving many functional areas.

\section{Which skills are required at the FEEI?}

Creativity skills are viewed as most important followed by engineering skills and environmental knowledge (Table 5). Managerial skills are viewed as least important. The high score for creativity skills is as expected, although the low scores for managerial skills are somewhat surprising, given that senior management commitment is often viewed as a key factor for successful FEEI ( Johansson, 2002 and Boks, 2006). A possible explanation is that the surveyed SMEs are by definition relatively small so an open "flat" organisational structure may be preferred and managerial skills might not be viewed as critical.

Environmental knowledge was considered important for creating successful eco-innovation products. This may seem obvious but it indicates that environmental knowledge is recognised as a specific expertise indispensible for eco-innovation. Despite the plethora of eco-design tools (as referenced in Baumann et al., 2002 for instance), which also intend to assist non-experts in the 
eco-innovation process, environmental knowledge is still an important skill. The processes by which eco-innovators undertake the FEEI may be informal, but companies systematically use certain tools. The nature of some of the main tools and concepts used (e.g., LCA; see next section) is specialist, which makes environmental knowledge indispensible.

\begin{tabular}{|l|l|}
\hline Skills & Number of respondents who found this skill critically important \\
\hline Creativity skills & 35 out of $42(72 \%)(91 \%$ found this reasonably or critically important) \\
Engineering Skills & 22 out of $42(53 \%)(86 \%$ found this reasonably or critically important) \\
Environmental knowledge & 20 out of $42(48 \%)(86 \%$ found this reasonably or critically important $)$ \\
Project management & 21 out of $42(45 \%)(76 \%$ found this reasonably or critically important) \\
\hline
\end{tabular}

Table 5. Main responses on survey question: "Please select how important the following staff skill sets/competences for developing successful eco-innovation projects teams within your company" (4point Likert-scale from "not at all important" to "critically important").

\subsection{Eco-innovation tools and concepts, mechanisms and processes are used at the FEEI}

\section{Which tools are used for concept generation?}

Frequency of tool and mechanism use during the initial concept generation phase of ecoinnovations differed significantly by respondent. Over $60 \%$ of the respondents used "Brainstorming" and "Pen and Pencil" techniques 'frequently' (Table 6). Forecasts, idea banks and seminars seem to be least used in the concept development phase (used 'frequently' by less than $10 \%$ of respondents). Experiments (time employees are allowed to experiment with or spend on their own environmentally innovative ideas) and informal discussion were used 'frequently' by over $40 \%$ of the respondents. A further question on experimentation showed that experimentation plays a significant role in the development of successful eco-innovations: $60 \%$ of the SMEs relied 'very much' on experimentation.

\begin{tabular}{|l|l|}
\hline Mechanism/ process & Number of respondents who frequently use this \\
\hline Brainstorming & 27 out of $42(64 \%)(88 \%$ used this at least sometimes) \\
Experiments & 26 out of $42(62 \%)(91 \%$ used this at least sometimes) \\
Informal discussions & 20 out of $42(47 \%)(81 \%$ used this at least sometimes) \\
\hline
\end{tabular}

Table 6. Main responses on survey question: "Please select the frequency you use of the following mechanism/processes during the initial concept generation stages of your eco-innovations" (4-point Likert-scale from "never" to "frequently use"). 


\section{Which "eco-design frameworks" are used at the FEEI?}

LCA is the "eco-design framework" most used in eco-innovation projects, but cradle-to-cradle and cleaner production principles are also used (Table 7). Concepts such as biomimicry (7\% use this 'all the time') are only used by some of the respondents. This suggests some SMEs use ecoinnovation tools and principles systematically.

\begin{tabular}{|l|l|}
\hline Eco-concepts & Number of respondents who use this eco-concept most or all of the time \\
\hline Life Cycle Assessment (LCA) & $\begin{array}{l}22 \text { out of } 42(53 \%)(88 \% \text { used this at least some of the time) } \\
\text { Cleaner Production }\end{array}$ \\
$\begin{array}{l}22 \text { out of } 42(47 \%)(78 \% \text { used this most or all of the time) } \\
\text { Cradle-to-Cradle (C2C) }\end{array}$ & 7 out of $42(45 \%)(76 \%$ used this most or all of the time) \\
\hline
\end{tabular}

Table 7 Main responses on survey question: "To what extent are the following eco-concepts being actively employed by the company when developing new environmental ideas and innovations?" (5point Likert-scale from "not at all" to "all the time").

Tool use thus may vary across projects within a company. Although companies use a range of tools (e.g. LCA) and concepts (Cradle-to-Cradle) systematically in FEEI, the full process FEEI process appears to include informal elements such as pen and pencil and informal discussions.

\subsection{Engagement of external parties}

\section{Which external information channels are used?}

The most important external information channels are the Internet (used 'some' to 'most of the time' by $90 \%$ of respondents) and networking events (used 'some' to 'most of the time' by over $70 \%$ of respondents). Overall many information channels are used: supplier communications, external databases, newspapers, industry expertise, seminars and consultants. According to the survey responses, external information is often obtained through informal encounters (nearly $90 \%$ of respondents use this 'some' or 'most of the time'). Kurkkio et al. (2011) also found that in the FEI for process innovations, informal discussion (e.g., at coffee breaks) is important. Nevertheless, nearly $80 \%$ of the respondents use formal meetings 'at least sometimes' to interact with external parties while intranets are used least to interact with stakeholders and other parties.

\section{Which external parties do SMEs engage with?}

In $60 \%$ of the cases ( 25 respondents) external actors play a role at the FEEI. The most important external parties involved in the eco-innovation process are customers and suppliers (at least 'some involvement' in around $80 \%$ of the cases). Customer demand may be the inspiration for new ideas; suppliers may help to achieve these ideas, but can also proactively help identify new opportunities. Haynest's idea originated from a client with an interest in natural packaging. Nearly $50 \%$ of the respondents interacted with industry clusters and technological institutes during the idea generation phase. Knowledge from those institutes may be obtained relatively informally: students, who temporarily joined the workforce at PaperFoam were a good source of new ideas. In our sample, few ideas originated from Non-Governmental Organisations (NGOs) who appear a relatively unimportant source for eco-ideation. 


\section{What are the mechanisms are used for interaction, and to store and share external trends?}

Eco-innovation decisions are made on the basis of conjectures about resource prices and future policies as suggested in Section "SME motivation and strategies for FEEI" it is difficult to study such conjectures in a survey as decision-making will be a complex process. However, the survey included a question on the mechanisms and tools used to store and share information and gain insights about future developments relevant for eco-innovation projects. Emails, informal discussions and meetings were the main mechanisms and tools by companies to share and store information (around 80\% found these 'reasonably' or 'critically important') whereas social media and company intranet were used least (less than $40 \%$ found these 'reasonably' or 'critically important').

\section{Conclusions and discussion}

This paper investigated the FEEI by exploring how SME eco-innovators conduct this process. Based on a sample of Dutch eco-innovators, a wealth of information about the motivations and targets and the mechanisms and tools used in FEEI was obtained.

First of all, it was found that FEEI is aligned with conventional business concerns such as satisfying (green) consumer demand and generating revenue, which resonates with the definition of eco-innovation by Reid and Miedzinski (2008) who view eco-innovations as competitively priced goods and services, with a significantly reduced environmental impact, rather than products with environmental benefits, which suffer from trade-offs (e.g., a higher price). This suggests that managers of the companies view eco-innovations as a business opportunity. Similar to normal innovations, the innovations are opportunity driven, are carried out with multiple objectives and build on past positive experiences. The main differences with the front-end process of normal innovation are the use of eco-design tools and greater importance of legislation. Our findings lend support to the econometric findings that for eco-innovations external sources of knowledge and information are more important than for innovation in general (Belil et al., 2011).

Second, SMEs conduct the FEEI in a systematic but informal manner: concepts and tools such as cradle-to-cradle and LCA are used systematically during the innovation process, but internal idea generation techniques are often informal (e.g., pen and pencil). One way to nurture sought-after creativity skills in employees is to allow them to experiment with their own eco-innovative ideas. Managers in SMEs may seek to leverage the advantages of the relatively small size of their companies and facilitate more informal meeting opportunities (e.g., by creating a shared communal space) to allow new ideas to emerge from informal conversations between staff. Subsequently, it is important to empower employees and give them time to allocate to potential new opportunities.

Thirdly, teams engaged in the FEEI appear to be multidisciplinary, and creativity skills and environmental knowledge are essential to the success of the team. Although 'environmental knowledge' is a specific skill at the FEEI, multidisciplinary teams have been found to promote creativity (see e.g., Kurtzberg, 2005). Perhaps surprisingly, marketing and managerial skills are viewed as less important, although the latter may be due to company size (small), and marketing may be more important at later stages of the innovation process. Although SMEs are small in size and generally have limited resources, this suggests that it would be helpful for managers of 
SMEs to recruit employees who (at least) acknowledge the importance of multidisciplinary work, are used to working in multidisciplinary environments, or have a 'mixed background' (i.e., have knowledge of or experience with multiple disciplines themselves).

Fourthly, similar to findings in studies of large companies (e.g., Johansson, 2002) SMEs engage with external stakeholders, such as customers and suppliers to generate novel ideas, but internal generation of eco-innovation ideas is also important. Moreover, SMEs, perhaps because limited by a relatively small innovation budget, have found creative ways to do "external idea generation", such as student placements. This shows that for managers in SMEs there are opportunities to source new ideas with a limited budget.

Finally, perhaps not surprisingly, it appears that the FEEI is not very different from the FEI for larger companies which has been more widely researched: suppliers and customers are involved in the innovation process (e.g., Kim and Wilemon, 2002), multi-disciplinary teams are formed, and creativity skills are valued (see e.g., Koen et al., 2001). However, for the FEEI specifically, environmental knowledge is required and specific design concepts (e.g., cradle-to-cradle) are used systematically by the eco-innovation frontrunners in the survey. The FEEI seems informal and management skills are not so important in FEEI teams. The latter findings may be due to the choice of our sample (SMEs).

What are the practical implications? Although this paper gives insights based on FEEI approaches by eco-innovative Dutch SMEs, these insights may also be relevant to other companies. Personal motivation (in addition to revenues) to develop eco-innovations was high in our sample. Although managers in SMEs might find it easier to embed their "green motivations" in corporate practices, larger companies should also recognise the importance of incorporating environmental considerations in the FEEI as eco-innovative "add-ons" at later stages may be expensive and less effective. The ability to 'eco-innovate' may become increasingly important under growing global pressures (see e.g., Royal Society, 2012), and may become a new source of competitive advantage. Hence, mastering the FEEI would be a key to business success and longevity. The tools required for this can perhaps be mastered more easily in big, resourceful companies, but larger companies may have difficulties in allowing the eco-innovation process to be open, informal and creative, aspects which contributed positively to the success of novel ecoinnovations. Some of the activities by the surveyed SMEs, such as student placements and allowing employees to experiment with new ideas can also be useful ways to develop new ideas, can be used in other companies too.

This research has a few limitations. Firstly, the sample is limited to Dutch SMEs who applied for the eco-innovation prize Het Ei van Columbus in the categories of product or production innovation. The sample has a country bias and a bias towards innovative firms (front-runners). The label front-runners is applied by us and based on the companies' (subjective) selfassessment of being eligible for a prize. In future research, companies may be asked for the percentage sales coming from eco-innovative products (as a more objective measure for determining whether a company is an eco-innovator). Second, the use of closed answer categories may have directed the responses of the SMEs to particular answers. However, for each question, SMEs were given the opportunity to write down their unique responses. Third, larger subsets samples of SMEs with different client bases (including Business-to-Government or B2G in brief, besides B2B and B2C) could have allowed for interesting (statically meaningful) 
analyses of differences in responses between these groups. A bigger sample size, and statistical analysis would have benefited the analysis in the paper.

Finally, more attention could have been given to aspects of organisational culture and management of innovation in the survey. Companies could have been asked questions about the ways in which eco-innovation projects differ from normal innovation projects as well, allowing us to better compare the front-end process of eco-innovation project with that of normal innovation projects.

The survey may be used in other countries and industries to understand how eco-innovators undertake the FEEI in different environments and whether there are differences in approach for particular industries and company sizes (e.g., multinational). Future research may investigate how large, successful eco-innovative companies have developed their FEEI processes: Have they "scaled up" informality and openness at the FEEI or are they using very formal innovation processes? Further empirical research on the FEEI may improve understanding how companies may successfully innovate in a resource-constrained world. Finally, detailed case analysis is needed to investigate the importance of the role of organisational culture, cross-functional interactions, integration of interests and management of part-whole relationships in innovation projects as important aspects of the innovation journey (van de Ven et al., 1999).

\section{References}

Arundel A., Kemp R. 2009. Measuring eco-innovation. UNU-MERIT Research Memorandum, 2009-017.

Ayyagari, M., Beck, T., Demirgüç-Kunt, A., 2007. Small and medium enterprises across the globe. Small Business Economics 29, 415-434.

Baumann, H., Boons, F., Bragd, A. 2002. Mapping the green product development field: engineering, policy and business perspectives. Journal of Cleaner Production, 10: 409-425.

Benyus, J. 1997. Biomimicry: Innovation Inspired by Nature. William Morrow \& Company, Inc: New York, USA.

Bertels, H., Kleinschmidt, E., Koen. P. 2011. Communities of Practice versus Organizational Climate: Which One Matters More to Dispersed Collaboration in the Front End of Innovation? Journal of Product Innovation Management, 28: 757-772.

Bocken, N., Allwood, J., Willey, A., King, J. 2011. Development of an eco-ideation tool to identify stepwise greenhouse gas emissions reduction options for consumer goods. Journal of Cleaner Production. 19 (12): 1279-1287.

Bocken, N., Allwood, J., Willey, A., King, J. 2012. Development of a tool to rapidly assess implementation difficulty and emissions reduction benefits of innovations. Technovation, 32 (1): 19-31.

Boks, C. 2006. The softside of ecodesign. Journal of Cleaner Production, 14: 1346-1356.

Bos-Brouwers, H. 2010. Corporate Sustainability and Innovation in SMEs: Evidence of Themes and Activities in Practice. Business Strategy and the Environment, 19, 417-435 
Brem, A. Voigt, K. 2009. Integration of market pull and technology push in the corporate front end and innovation management-Insights from the German software industry, Technovation, 29: 351-367.

Buttol , P., Buonamici, R., Naldesi, L., Rinaldi, C., Zamagni, A., Mason, P. 2012. Integrating services and tools in an ICT platform to support eco-innovation in SMEs. Clean Technologies and Environmental Policy, 14, (2), 211-221.

Byggeth, S., Hochschorner, E. 2006. Handling trade-offs in Ecodesign tools for sustainable product development and procurement. Journal of Cleaner Production, 14: 1420-1430.

Chandy, R., Tellis, G. 2000. The incumbents curse: incumbency, size, and radical product innovation. Journal of Marketing, 64, 1-17.

Christensen, C. 1997. The innovator's dilemma. When new technologies cause great firms to fail. Harvard Business School Press, Boston (MA).

Cooper, R. 2008. Perspective: The Stage-Gate ${ }^{\circledR}$ Idea-to-Launch Process - Update, What's New and NexGen Systems. Journal of Product Innovation Management. 25: 213-232.

Cramer, J., Stevels, A. 1997. Strategic Environmental Product Planning within Philips Sound \& Vision. Environmental Quality Management, 7 (1): 91-102.

de Brentani, U., Reid, S. 2012. The Fuzzy Front-End of Discontinuous Innovation: Insights for Research and Management. Journal of Product Innovation Management, 29 (1): 70-87.

Ehrenfeld, J. 2008. Sustainability by design: A subversive Strategy for Transforming Our Consumer Culture. Yale University Press: New Haven, CT.

EU. 2012. Small companies, big ideas. Retrieved from the WWW, December 2012:

http://ec.europa.eu/environment/ecoap/about-eco-innovation/policies-matters/eu/20121029-smallcompanies-big-ideas_en.htm

Geerts, M. Personal interview. May 2010, Barneveld, the Netherlands.

Hart, S., Milstein, M. 2003. Creating sustainable value. Academy of Management Executive, 17 (2): 5669.

Hassi, L., Peck, D., Dewulf, K., Wever, R. 2009. Sustainable Innovation - Organization and goal finding, Industrial Engineering and Management, Helsinki University of Technology, Espoo, Finland.

Haynest. 2010. Haynest. Retrieved from the WWW, 15 May 2010:

http://www.Haynest.com/Flex/Site/Page.aspx?PageID=\&Lang=UK

Herman, R., Ardekani, A., Ausubel, J. 1990. Dematerialization. Technological Forecasting and Social Change, 38: 333-347.

Herstatt, C., Verworn, B. 2001. The "Fuzzy Front End" of Innovation. Working Paper No. 4, Department of Technology and Innovation Management, Technical University of Hamburg.

Het Ei van Columbus. 2010. Het Ei van Columbus. Retrieved from the WWW, 20 May 2010: http://www.ei-van-columbus.nl/ 
ISO 14040. 2006. Environmental management — Life cycle assessment. Principles and framework. International Organisation for Standardization, Geneva, Switzerland.

Johansson, G. 2002. Success factors for integration of ecodesign in product development - a review of state-of-the-art. Environmental Management and Health, 13 (1): 98-107.

Karlsson, R., Luttropp , C. 2006. EcoDesign: what's happening? An overview of the subject area of EcoDesign and of the papers in this special issue. Journal of Cleaner Production, 14: 1291-1298

Kemp, R. 2010. Eco-innovation: Definition, Measurement and Open Research Issues. Economia politica. Journal of Analytical and Institutional Economics, 27: 397-420.

Khurana, A., Rosenthal, S. 1998. Towards holistic "front ends" in new product development. Journal of Product Innovation Management 15: 57-74.

Kim, J., Wilemon, D. 2002. Focusing the fuzzy front-end in new product development. R\&D management, 32 (4): 269-279.

Knoors, G. Personal interview. June 2010, Eindhoven, the Netherlands.

Koen, P., Ajamian, G., Burkart, R., Clamen A., Davidson, J., D'Amore, R., Elkins, C., Herald, K., Incorvia, M., Johnson, A., Karol, R., Seibert, R., Slavejkov, A., Wagner, K. 2001. Providing clarity and a common language to the "fuzzy front end". Research and Technology Management, 44 (2): 46-55.

Koen, P. Ajamin, G., Burkart, R., Clamen, A., Fisher, E., Fountoulakis, S., Johnson, A., Pushpinder, P., Seibert, R. 2002. Fuzzy front End: effective methods, tools and techniques. In: Belliveau, P., Griffin, A., Somermeyer, S. 2002 (Eds.). The PDMA toolbook for new product development (S. 5-35). John Wiley \& Sons, New York.

Kurkkio, M., Frishammar, J., Lichtenhaler, U. 2011. Where process development begins: A multiple case study of front end activities in process firms. Technovation, 31 (9): 490-504.

Kurtzberg, T. 2005. Feeling Creative, Being Creative: An Empirical Study of Diversity and Creativity in Teams, Creativity Research Journal, 17:1, 51-65.

Luttropp, C., Lagerstedt, J., 2006. EcoDesign and The Ten Golden Rules: generic advice for merging environmental aspects into product development, Journal of Cleaner Production, 14, (15-16): 1396-1408.

McDonough, W., Braungart, M. 2002. Cradle-to-Cradle: Remaking the way we make things. North Point Press, New York.

Nissen, U., 1995. A methodology for the development of cleaner products. Journal of Cleaner Production, 3 (1-2): 83-87.

Petala, E., Wever, R., Dutilh, C., Brezet, H. 2010. The role of new product development briefs in implementing sustainability: a case study. Journal of Engineering and Technology Management, 27: 172182.

PaperFoam. 2010. Sustainability-datasheet. Retrieved from the WWW, 14 January 2011: http://www.paperfoam.com/downloads/algemeen/PaperFoam\%20CD-

DVD\%20tray\%20Sustainability\%20datasheet\%2001.01.07.pdf 
Reid, S., de Brentani, U. 2004. The fuzzy front end of new product development for discontinuous innovations: A theoretical model. Journal of Product Innovation Management, 21 (3): 170-184.

Reid, A, Miedzinski, M. 2008. Eco-innovation: Final report for sectoral Innovation Watch. Technopolis group. Retrieved from the WWW, 14 January 2012: http://www.technopolisgroup.com/resources/downloads/661_report_final.pdf

Saling, P., Kicherer, A., Dittrich-Krämer, B., Wittlinger, R., Zombik, W., Schmidt, I., Schrott, W., Schmidt, S. 2002. Eco-efficiency Analysis by BASF: The Method. International Journal of Life Cycle Assessment, 7 (4): 203-218.

Scientific Applications International Corporation (SAIC). 2006. Life cycle assessment: principles and practice. National risk management research laboratory office of research and development U.S.

Environmental Protection Agency. Retrieved from the WWW 15 January 2012:

http://www.epa.gov/nrmrl/lcaccess/pdfs/600r06060.pdf

Van Berkel, R., Willems, E., Lafleur, M. 1997. Development of an industrial ecology toolbox for the introduction of industrial ecology in enterprises - I. Journal of Cleaner Production, 5 (1-2): 11-25.

Van Hemel, C., Brezet, J. 1997. Ecodesign; A promising approach to sustainable production and consumption. UNEP, Paris.

Van Hemel, C., Cramer, J. 2002. Barriers and stimuli for ecodesign in SMEs. Journal of Cleaner Production, 10: 439-445.

\section{Appendices}

\section{Appendix A. Industries covered in sample}

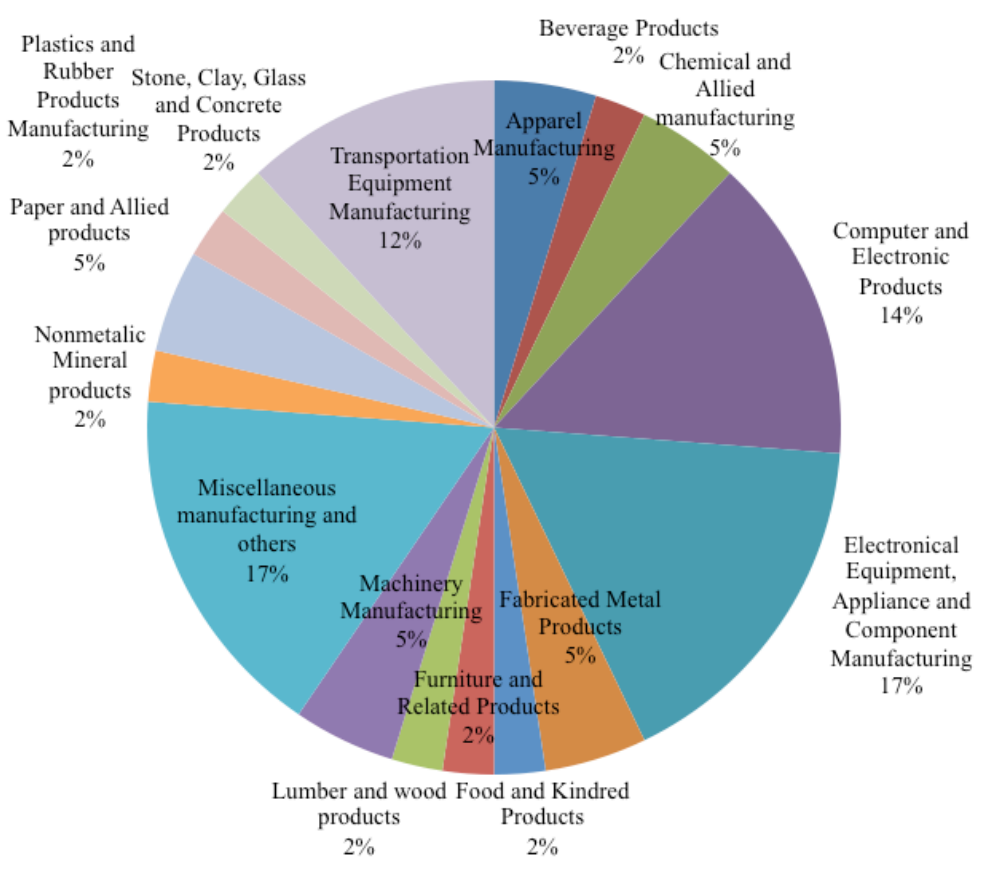

